\title{
Antibiotic expected effectiveness and cost under real life microbiology: evaluation of ertapenem and ceftriaxone in the treatment of community- acquired pneumonia for elderly patients in Spain
}

\author{
This article was published in the following Dove Press journal: \\ ClinicoEconomics and Outcomes Research \\ 13 February 2014 \\ Number of times this article has been viewed
}

\section{Santiago Grau' \\ Virginia Lozano ${ }^{2}$ \\ Amparo Valladares ${ }^{3}$ \\ Rafael Cavanillas ${ }^{4}$ \\ Yang $\mathrm{Xie}^{5}$ \\ Gonzalo Nocea ${ }^{3}$}

'Hospital del Mar, Barcelona, Spain; ${ }^{2}$ Pharmacoeconomics and Outcomes Research Iberia, Madrid, Spain; ${ }^{3}$ Outcomes Research Merck Sharp and Dohme Ltd, Madrid, Spain; ${ }^{4}$ Medical Affairs, Merck Sharp and Dohme Ltd, Madrid, Spain; ${ }^{5}$ Global Health Outcomes, Merck Sharp and Dohme Ltd, Whitehouse Station, NJ, USA
Correspondence: Santiago Grau Hospital el Mar, Passeig Marítim 25-29, 08003 Barcelona, Spain

Tel +34932483000

Fax +34932483254

Email sgrau@parcdesalutmar.cat
Background: Clinical efficacy of antibiotics may be affected by changes in the susceptibility of microorganisms to antimicrobial agents. The purpose of this study is to assess how these changes could affect the initial efficacy of ertapenem and ceftriaxone in the treatment of community-acquired pneumonia (CAP) in elderly patients and the potential consequences this may have in health care costs.

Methods: Initial efficacy in elderly was obtained from a combined analysis of two multicenter, randomized studies. An alternative scenario was carried out using initial efficacy data according to the pneumonia severity index (PSI). Country-specific pathogens distribution was obtained from a national epidemiological study, and microbiological susceptibilities to first- and secondline therapies were obtained from Spanish or European surveillance studies. A decision analytic model was used to compare ertapenem versus ceftriaxone for CAP inpatient treatment. Inputs of the model were the expected effectiveness previously estimated and resource use considering a Spanish national health system perspective. Outcomes include difference in proportion of successfully treated patients and difference in total costs between ertapenem and ceftriaxone. The model performed one-way and probabilistic sensitivity analyses.

Results: First-line treatment of CAP with ertapenem led to a higher proportion of successfully treated patients compared with ceftriaxone in Spain. One-way sensitivity analysis showed that length of stay was the key parameter of the model. Probabilistic sensitivity analysis showed that ertapenem can be a cost-saving strategy compared with ceftriaxone, with a 59\% probability of being dominant (lower costs with additional health benefits) for both, elderly patients ( $>65$ years) and patients with PSI $>3$.

Conclusion: The incorporation of the current antimicrobial susceptibility into the initial clinical efficacy has a significant impact in outcomes and costs in CAP treatment. The treatment with ertapenem compared with ceftriaxone resulted in better clinical outcomes and lower treatment costs for two segments of the Spanish population: elderly patients and patients with severe pneumonia (PSI >3).

Keywords: antibacterial agent, bacterial infection, cost-effectiveness analyses, drug costs, Spain, aged

\section{Introduction}

Community-acquired pneumonia (CAP) is a widespread disease with important implications for health care systems worldwide. For industrialized countries, CAP represents the leading cause of death due to infectious disease. ${ }^{1,2}$ The incidence of CAP in Spain ranges from 5-11 per 1,000 adults, rising to 25-35 cases per 1,000 in 
elderly people over age $65 .^{3}$ Hospital admission is common for elderly patients ${ }^{3}$ and is associated with significant use of health care resources and costs. ${ }^{4}$

Given the inherent difficulty of determining the cause of CAP (an etiological diagnosis is only established in $40 \%-60 \%$ of the cases $)^{5}$ empiric antibiotic treatment is often required. The majority of patients with mild-to-moderate CAP are treated in the community setting with empirical antimicrobial therapy. Patients with more serious disease or who are elderly or have comorbidities may be hospitalized, and antimicrobial therapy is usually started empirically. Thus, it is important that the choice of antimicrobial therapy ensures appropriate coverage of potentially drug-resistant strains based on local antimicrobial resistance pattern. Ertapenem and ceftriaxone are commonly used as empiric treatment in monotherapy or in combination with macrolides if infection with atypical pathogens is suspected. ${ }^{6}$ Ertapenem is a carbapenem, active against the majority of bacterial pathogens causing most routine community-acquired infections, including enterobacteriaceae and anaerobes. ${ }^{7}$ Ceftriaxone is a third-generation cephalosporin with broad-spectrum activity against Gram-positive and Gram-negative bacteria. ${ }^{8}$ Both antibiotics are potent drugs with broad-spectrum antimicrobial activity, widely used to treat elderly patients in whom pneumonia tends to follow severe courses due to their high rates of comorbidities. ${ }^{9-11}$

According to international guidelines on the management of CAP, ertapenem and ceftriaxone were recommended for hospital ward treatment as preferred beta-lactam agents. ${ }^{12}$ The clinical efficacy of ceftriaxone and ertapenem was compared in two randomized controlled trials, where these two antibiotics showed equivalence. ${ }^{13-16}$ Nonetheless, these efficacy results are limited by the controlled trials' conditions and may not be representative of clinical practice. Furthermore, the etiologic profile of CAP may differ considerably from one geographic region to another, and the microbial susceptibility to these antibiotics may have changed over the years, depending on their prescribing patterns and extensive use. The primary objective of this study was to incorporate the dynamics in microbiological susceptibilities and pathogens distribution for elderly patients in Spain into the initial clinical efficacy described for ertapenem and ceftriaxone in patients with CAP. The expected effectiveness obtained for ertapenem and ceftriaxone will be used to compare the cost impact in the treatment of hospitalized patients with CAP in Spain.

\section{Material and methods}

\section{Clinical data}

Initial clinical efficacies of ertapenem and ceftriaxone were extracted from the combined analysis performed by
Ortiz-Ruiz et $\mathrm{al}^{15}$ of two multicenter randomized, doubleblind studies. ${ }^{13,14}$ In these two studies, the efficacy and safety of ertapenem $1 \mathrm{~g}$ once a day for the treatment of CAP were compared with those of ceftriaxone $1 \mathrm{~g}$ once a day, and patients were stratified according to pneumonia severity index (PSI) $(\leq 3$ or $>3$ ) or age ( $\leq 65$ or $>65$ years). In the combined analysis, ${ }^{15}$ clinical cure rates were equivalent for both treatments: $92.0 \%$ (95\% confidence interval [CI]: 89.2-94.8) for ertapenem and 91.8\% (95\% CI: 88.7-95.0) for ceftriaxone. Nonetheless, a slight difference in clinical cure rates was reported for elderly patients (age $>65$ years), with $93.6 \%$ (95\% CI: 89.6-97.7) with ertapenem and 91.3\% (95\% CI: 86.1-96.5) with ceftriaxone, but no statistically significant difference was assumed between the groups.

It was assumed that patients with clinical failure to firstline treatment with ertapenem or ceftriaxone, ie, lack of clinical response at day 3 after treatment, ${ }^{17}$ are treated with another second-line treatment. According to recommendations in Spanish guidelines for the empiric treatment of CAP, a second-line treatment with imipenem/cilastatin $1 \mathrm{~g}$ three times a day was considered in our model. ${ }^{6}$ The initial clinical efficacy of imipenem/cilastatin was extracted from a randomized prospective study conducted in elderly patients with CAP. ${ }^{18}$ It was assumed that failure of second-line therapy has a mortality rate of $0.9 \%$, based on the Fine et al criteria mix of the population ${ }^{19}$ (Table 1).

The data regarding pathogens' distribution and their current microbiological susceptibility profile were then combined to estimate the overall susceptibility against ertapenem, ceftriaxone, and imipenem. Finally, the expected effectiveness for each antibiotic was obtained by incorporating the overall susceptibility into the initial clinical efficacy (Table 2).

The pathogens' distribution was obtained from the study of Vila-Corcoles et al, ${ }^{10}$ in which 473 patients with CAP, aged $\geq 65$ years, were prospectively studied between 2002 and 2005 in the region of Tarragona, Spain. The etiology was established in $131(36.6 \%)$ patients, and results showed Streptococcus pneumoniae as the most common pathogen of CAP in elderly patients.

The current microbiological susceptibility profile was obtained from the in vitro activity of ertapenem, ceftriaxone, and imipenem against the pathogens isolated from patients suffering from respiratory tract infections in Spain. In the absence of locally conducted studies, in vitro susceptibility data from European multicenter trials, including Spanish centers, were used. ${ }^{20-23}$ There were pathogens whose susceptibility data against ertapenem, ceftriaxone, and imipenem were not found in the literature; 
Table I Efficacy and cost data for decision-tree model of CAP in Spain (base-case scenario)

\begin{tabular}{|c|c|c|c|}
\hline & Ertapenem-arm & Ceftriaxone-arm & Source \\
\hline $\begin{array}{l}\text { Initial efficacy (clinical response) } \\
(\text { mean, }[95 \% \mathrm{Cl}])\end{array}$ & $0.936(0.896-0.977)$ & $0.913(0.86 \mid-0.965)$ & Age $>65$ years subgroup based on Ortiz-Ruiz et a $\left.\right|^{15}$ \\
\hline $\begin{array}{l}\text { Second-line antibiotic efficacy } \\
\text { (mean, }[95 \% \mathrm{Cl}] \text { ) }\end{array}$ & $0.863(0.81 \mathrm{I}-0.915)$ & $0.863(0.811-0.915)$ & Romanelli et al ${ }^{18}$ \\
\hline $\begin{array}{l}\text { Cost per day of first-line } \\
\text { antibiotic treatment }\end{array}$ & $€ 39.08$ & $€ 7.20$ & $\begin{array}{l}\text { Unit cost from Botplus; }{ }^{29} \text { dose information from } \\
\text { SEPAR guideline }{ }^{6}\end{array}$ \\
\hline $\begin{array}{l}\text { Cost per day of second-line } \\
\text { antibiotic treatment (imipenem) }\end{array}$ & $€ 40.38$ & $€ 40.38$ & $\begin{array}{l}\text { Unit cost from Botplus; }{ }^{29} \text { dose information from } \\
\text { SEPAR guideline }^{6}\end{array}$ \\
\hline Cost of hospitalization per day & $€ 419.3$ & $€ 419.3$ & $\begin{array}{l}\text { Hospitalization cost based on weighted DRGs } \\
89 \text { and } 90 \text { from Spanish Ministry of Health }{ }^{27}\end{array}$ \\
\hline $\begin{array}{l}\text { Length of stay for patients with } \\
\text { clinical success (mean, }[95 \% \mathrm{Cl}] \text { ) }\end{array}$ & $8.4(8.1-8.7)$ days & $8.4(8.1-8.7)$ days & $\begin{array}{l}\text { Treatment duration based on Menéndez et a }{ }^{26} \\
\text { and DRGs update }{ }^{27}\end{array}$ \\
\hline $\begin{array}{l}\text { Length of stay for patients with } \\
\text { clinical failure (mean, }[95 \% \mathrm{Cl}] \text { ) }\end{array}$ & I6.5 (14.8-18.2) days & 16.5 (14.8-18.2) days & $\begin{array}{l}\text { Treatment duration based on Menéndez et } \mathrm{a}^{26} \\
\text { and DRGs update }{ }^{27}\end{array}$ \\
\hline
\end{tabular}

Abbreviations: CAP, community-acquired pneumonia; $\mathrm{Cl}$, confidence interval; DRGs, diagnosis-related groups; SEPAR, Spanish Society of Chest Disease and Thoracic Surgery.

these pathogens ( $18 \%$ of the total distribution) were Chlamydia pneumoniae, Legionella, Moraxella catarrhalis, Streptococcus sanguis, Streptococcus salivarius, Nocardia, Peptococcus, Mycobacterium tuberculosis, and Coxiella burnetii, all which were assumed had $0 \%$ susceptibility to ertapenem, ceftriaxone, and imipenem.

\section{Model overview}

A previously published decision-tree mode ${ }^{24,25}$ was adapted to evaluate the expected effectiveness in the cost impact of ertapenem relative to ceftriaxone for the treatment of CAP in an elderly population. A hypothetical cohort of 1,000 patients received either ceftriaxone $1 \mathrm{~g}$ once a day or ertapenem $1 \mathrm{~g}$ once a day at model entry. The time horizon for the analysis was equivalent to the treatment duration of a CAP episode, including a possible second-line treatment. As the total time is shorter than 1 year, no discounting of costs or outcomes was applied. The analysis was performed from the perspective of the Spanish national health system. Thus, indirect health care costs and productivity loss were not included.

The basic scheme of the decision-tree is presented in Figure 1, depicting the most relevant outcomes in the treatment of CAP. A single decision node represents a choice

Table 2 Initial efficacy, overall susceptibility, and expected effectiveness for ertapenem, ceftriaxone, and imipenem (basecase scenario)

\begin{tabular}{llll}
\hline & Ertapenem & Ceftriaxone & Imipenem \\
\hline Initial efficacy & 0.94 & 0.91 & 0.88 \\
Estimated overall & 0.76 & 0.71 & 0.78 \\
$\begin{array}{l}\text { susceptibility } \\
\text { Expected effectiveness }\end{array}$ & 0.71 & 0.65 & 0.69 \\
\hline
\end{tabular}

Notes: Estimated overall susceptibility is the $\Sigma \%$ pathogen's distribution. $\%$ pathogen's susceptibility; Expected effectiveness is initial efficacy•estimated overall susceptibility. between the two alternatives, ertapenem or ceftriaxone, for treating CAP in elderly patients. Both ertapenem and ceftriaxone can result in a successful outcome with a certain probability. When ertapenem or ceftriaxone is not efficacious, patients are treated with another (secondline) antibiotic, which again has a certain probability of success. If this second antibacterial treatment fails, the outcome can be either fatal or there will be sequelae as a result of the bacterial infection. The costs associated with each alternative were calculated based on the expected effectiveness.

\section{Resource use and costs}

According to Menéndez et al data, ${ }^{26}$ the mean length of hospital stay (LOS) for CAP treatment was 9.4 days in case of clinical success, and 18.5 days in case of treatment failure. It was assumed that the patient was receiving intravenous therapy throughout the hospitalization period. In order to update these values from 2005, the variation of mean LOS was studied across the 2005-2011 period, based on diagnosis-related group (DRG) data for CAP in Spain. The mean days of hospital stay, weighted according to the number of patients for DRGs 89 and 90 (pneumonia simple and pleurisy with and without complications in patients over 17 years, respectively) had decreased 10.6\% from 2005-2010. ${ }^{27}$ This reduction in the LOS was applied to Menéndez et al data, ${ }^{26}$ obtaining a mean LOS of 8.4 days for CAP with clinical success and 16.5 days in the case of treatment failure (Table 1). Hospitalization cost was also obtained from the weighted DRGs 89 and $90^{27}$ and was updated to 2011 values based on the consumer price index. Drug costs were calculated from the recommended dose in clinical guidelines, while considering the laboratory sales price resulting from applying the commercial margins established ${ }^{28}$ on the public retail price. ${ }^{29}$ 


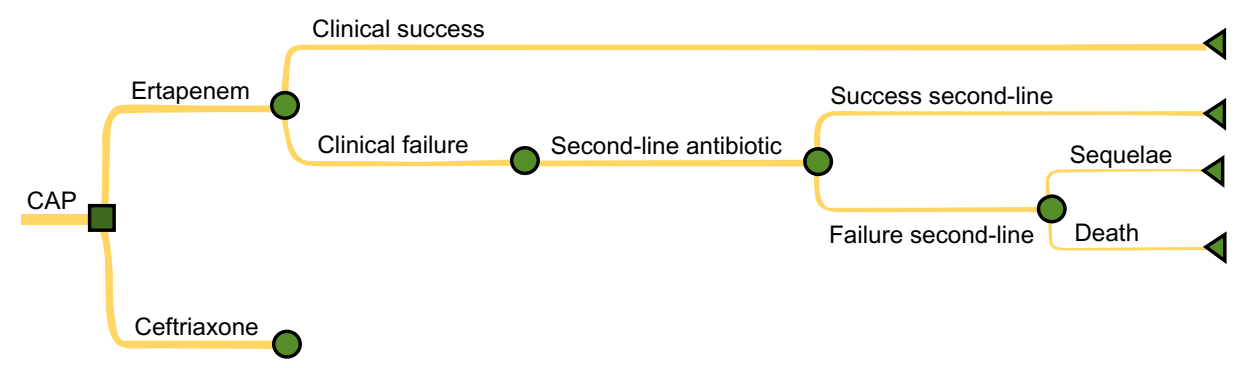

Figure I Decision-tree model for treatment of community acquired pneumonia (CAP).

Furthermore, a 7.5\% deduction based on the Royal Decree-law 8/2010 of May 20, was applied to the laboratory sales price of ertapenem. ${ }^{30}$ The price of ceftriaxone was based on the least expensive generic medication.

\section{Alternative scenario}

The PSI is a validated risk stratification instrument, which can help in identifying CAP patients with high risk of mortality. The PSI involves calculating a score, which places a given patient into one of five risk classes. Classes I, II, and III are at low risk for death, and may be considered for outpatient treatment, and risk classes IV and V should usually be hospitalized. ${ }^{19}$ In this study, an alternative scenario was considered using the data of clinical cure rates for patients with PSI $\leq 3$ and PSI $>3$ from the combined analysis performed by Ortiz-Ruiz et al. ${ }^{15}$ For patients with PSI $\leq 3$, the clinical cure rates for the ertapenem-arm and ceftriaxonearm were 92.7\% (95\% CI: 89.6-95.8) and 93.8\% (95\% CI: 90.5-97.1), respectively, while patients with PSI $>3$ showed clinical cure rates of $90.9 \%$ (95\% CI: 83.8-96.2) in the ertapenem cohort and $87.1 \%$ (95\% CI: 79.9-94.2) in the ceftriaxone cohort.

\section{Sensitivity analysis}

To test the robustness of our evaluation, extensive sensitivity analyses were performed. One-way sensitivity analysis was conducted to determine the key drivers of the model by modifying independently the following parameters over a range of $\pm 10 \%$ : initial clinical efficacy, expected effectiveness, LOS in case of clinical success and clinical failure, cost of hospitalization per day, and unit cost of ertapenem, ceftriaxone, and imipenem. For the most sensitive parameters, LOS during first- and second-line treatment, additional one-way sensitivity analyses were carried out.

Probabilistic sensitivity analysis provides a comprehensive assessment of the impact of second-order uncertainty by assuming simultaneous variations in all of the model parameters. In our analysis, a Monte Carlo simulation was performed with 1,000 iterations, and its outcomes were expressed as a cost-effectiveness plot. For the expected effectiveness and mortality, beta distributions were used. For treatment duration and LOS, triangular distributions (defined by the CI limits of each estimate) were conservatively chosen given the lack of data in the literature. The point estimates, ranges, and parameters for the distributions are listed in Table 3. For each simulation, a random value was sampled from these distributions, and the outcomes of the model were calculated.

\section{Results}

\section{Base-case}

Under the base-case scenario, and after considering the distribution of pathogens in an elderly population with CAP and their

Table 3 Probability estimates, ranges, and distribution parameters used in the model (base-case scenario)

\begin{tabular}{|c|c|c|c|c|c|c|}
\hline \multirow[t]{2}{*}{ Expected effectiveness } & \multirow[t]{2}{*}{ Estimate } & \multicolumn{2}{|c|}{ Range } & \multicolumn{3}{|c|}{ Parameters } \\
\hline & & Low & High & SE & Alpha & Beta \\
\hline Ertapenem & 0.71 & 0.68 & 0.74 & 0.02 & 603.00 & 246.30 \\
\hline Ceftriaxone & 0.648 & 0.61 & 0.68 & 0.02 & 414.12 & 224.95 \\
\hline Second-line treatment & 0.682 & 0.61 & 0.75 & 0.03 & 121.48 & 56.64 \\
\hline Mortality & 0.22 & 0.14 & 0.30 & 0.04 & 23.87 & 84.64 \\
\hline $\begin{array}{l}\text { Treatment duration and LOS for patients } \\
\text { with clinical success }\end{array}$ & 8.4 & 8.1 & 8.7 & - & - & - \\
\hline $\begin{array}{l}\text { Treatment duration and LOS for patients } \\
\text { with clinical failure }\end{array}$ & 16.5 & 14.8 & 18.2 & - & - & - \\
\hline
\end{tabular}

Abbreviations: LOS, length of hospital stay; SE, standard error. 
current microbiologic susceptibility profile, the proportion of successfully treated patients with ertapenem and ceftriaxone is expected to be $71.0 \%$ and $64.8 \%$, respectively (Table 4 ). The higher drug cost of $€ 426$ per patient in the ertapenem-arm compared to $€ 243$ in the ceftriaxone-arm was compensated by the lower resource use cost per patient, mainly hospitalization costs (ertapenem-arm: $€ 4,514$; ceftriaxone-arm: $€ 4,726$ ). The calculated net difference in antibiotic drug and hospital costs represents a savings of $€ 29$ per patient with ertapenem relative to ceftriaxone (Figure 2).

\section{Alternative scenario}

Under the alternative scenario, clinical cure rates according to PSI scores were considered. The outcomes of the model obtained for patients with PSI $\leq 3$ and PSI $>3$ are summarized in Table 5. For patients with PSI $\leq 3$, the proportion of successfully treated patients obtained for the ertapenem-arm and ceftriaxone-arm was $70.3 \%$ and $66.5 \%$, respectively. The total cost for the treatment of CAP, including drugs and hospitalization costs, was estimated to be $€ 4,965$ in the ertapenem-arm and $€ 4,899$ in the ceftriaxone-arm, representing a savings of $€ 66$ when CAP is treated with ceftriaxone relative to ertapenem in patients with PSI $\leq 3$. For patients with PSI $>3$, a greater difference in the proportion of successfully treated patients was obtained between ertapenem and ceftriaxone, with $68.3 \%$ being the proportion of successfully treated patients in the ertapenem-arm and $61.8 \%$ in the ceftriaxonearm. The total cost of CAP treatment was lower in the ertapenem-arm, $€ 5,042$ versus $€ 5,086$ in the ceftriaxone-arm, representing a savings of $€ 44$ when ertapenem is considered for the treatment of CAP in patients with PSI $>3$.

\section{Sensitivity analysis}

In the one-way sensitivity analysis, the parameter most impacting the results was the LOS. As discussed above,

Table 4 Clinical and economic results of the model for the basecase scenario

\begin{tabular}{llll}
\hline & $\begin{array}{l}\text { Ertapenem- } \\
\text { arm }\end{array}$ & $\begin{array}{l}\text { Ceftriaxone- } \\
\text { arm }\end{array}$ & Differences \\
\hline $\begin{array}{l}\text { First-line clinical } \\
\text { failures avoided }\end{array}$ & $71.0 \%$ & $64.8 \%$ & $6.2 \%$ \\
$\begin{array}{l}\text { Cost per patient } \\
\text { Drug cost }\end{array}$ & $€ 426$ & $€ 243$ & $€ 183$ \\
$\begin{array}{l}\text { per patient } \\
\text { Resource use } \\
\text { cost per patient }\end{array}$ & $€ 4,514$ & $€ 4,726$ & $-€ 212$ \\
Total cost & $€ 4,940$ & $€ 4,969$ & $-€ 29$ \\
\hline
\end{tabular}

Note: The base-case scenario assumed that data from the initial clinical efficacy of ertapenem and of ceftriaxone are based on Ortiz-Ruiz et al. ${ }^{15}$

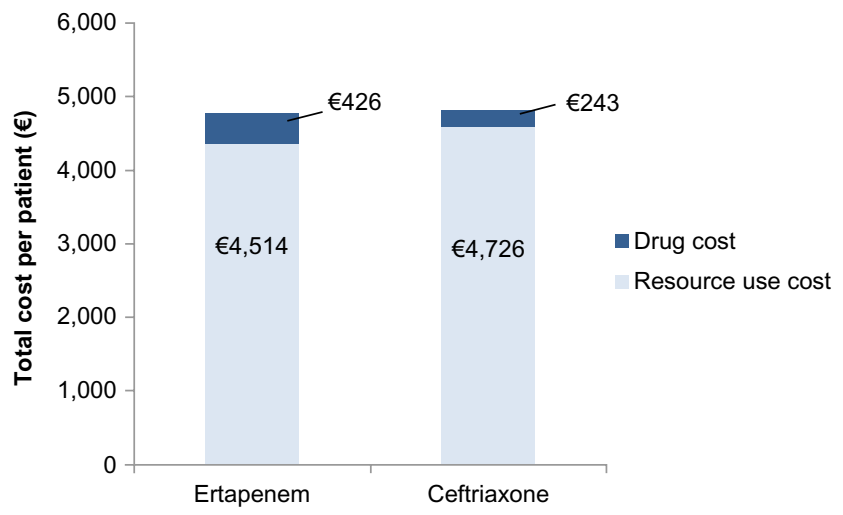

Figure 2 Drug and resource costs per patient for ertapenem- and ceftriaxone-arm (base-case scenario).

the mean days of hospital stay observed for DRGs 89 and 90 decreased by $10.6 \%$ across the $2005-2011$ period. The impact of this decrease, considering both equal and different rates for first- and second-line treatment, is represented in Figure 3. When LOS decreases at the same rate for first- and second-line treatment, there were no significant differences with the base-case results (Figure 3A). Nonetheless, higher savings were observed for the ertapenem-arm relative to ceftriaxone when LOS during first-line treatment decreased to a greater extent than for second-line (Figure 3B). When LOS was reduced at a higher rate for second-line, the difference in total costs between ertapenem and ceftriaxone was reduced as represented in Figure 3C.

The results obtained for the other parameters are represented for the base-case in the tornado diagram of Figure 4 . As can be seen in this chart, where the variables tested in the sensitivity analysis are ordered according to their (decreasing) impact on the result, the variables with the largest impact on the result are the treatment cost with ertapenem and the unit cost per day of hospitalization. Nevertheless, changes in these two variables within the $\pm 10 \%$ range do not produce a change in the outcomes, resulting in a cost reduction for both variables across the whole tested range (as it also happened for all other variables in the sensitivity analysis).

The results of the probabilistic analysis showed that for the base-case ( $>65$ years), ertapenem is a dominant strategy (less costly with additional benefits) in 59\% of simulations (Figure 5). In those cases where ertapenem showed additional benefits with higher costs, there is a $44 \%$ likelihood that the treatment with ertapenem offsets by at least $50 \%$ the difference in drug costs between ertapenem and ceftriaxone. In the alternative scenario, PSI $>3$ and PSI $\leq 3$, there is a $59 \%$ and $34 \%$ likelihood that ertapenem would be a dominant strategy, respectively. 
$\multimap$ Base-case (>65 years) $\longrightarrow$ Alternative scenario $(\mathrm{PSI}>3)$
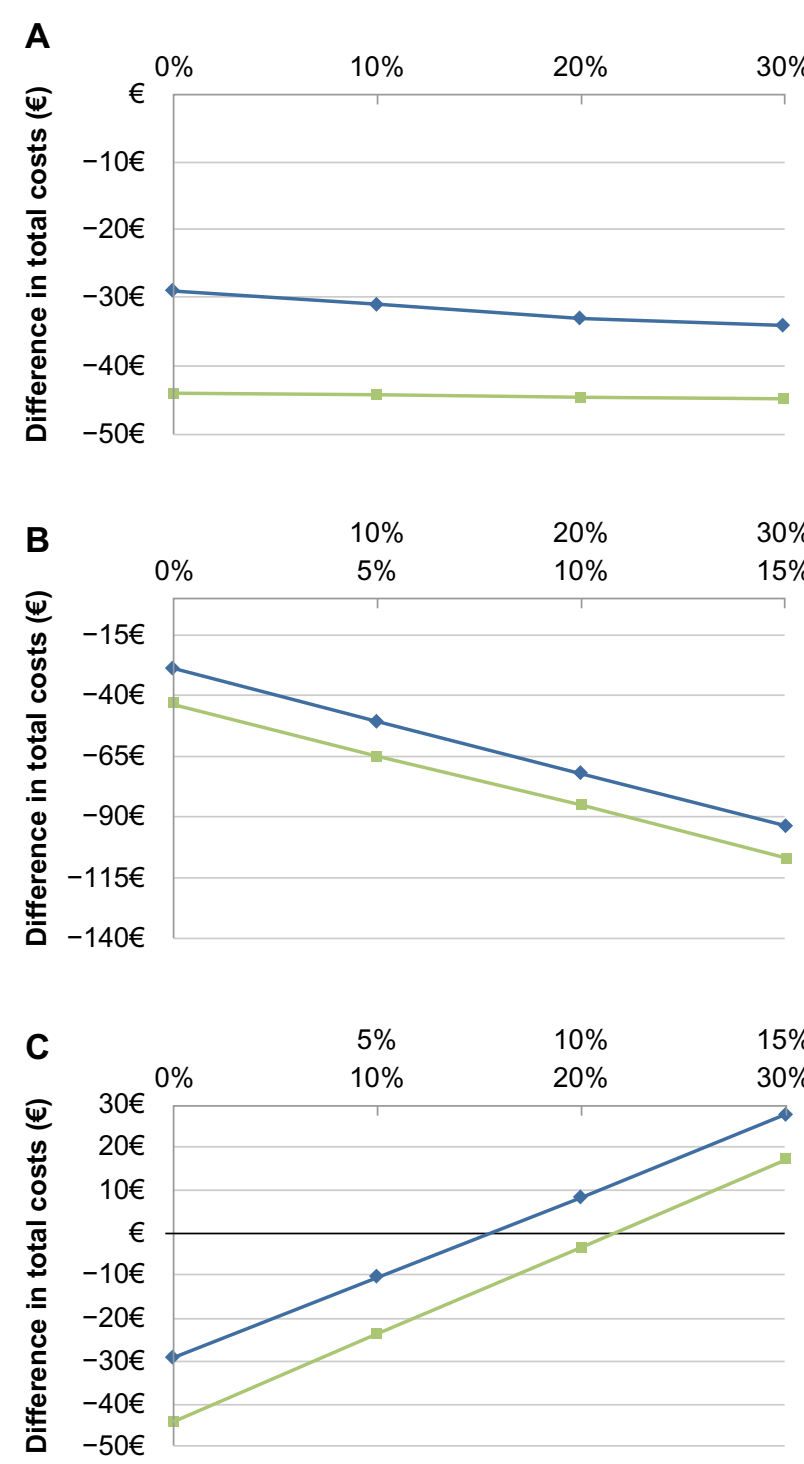

\section{LOS reduction in first- and second-line} treatment

\section{LOS reduction in first-line treatment \\ LOS reduction in second-line treatment}

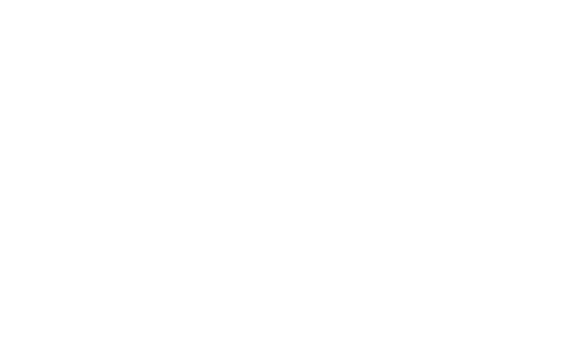

LOS reduction in first-line treatment LOS reduction in second-line treatment

Figure 3 One-way sensitivity analysis for length of stay.

Notes: (A) LOS decreases at the same rate for first- and second-line treatment. (B) LOS decreases to a greater extent for the first line treatment. (C) LOS decreases to a greater extent for the second line treatment.

Abbreviation: LOS, length of hospital stay.

\section{Discussion}

To our knowledge, this is the first study aimed to explore the impact of the evolution of the microbiological profile for CAP in Spain, and illustrates how the modulation of the initial clinical efficacy through the current microbial susceptibility profile and the etiology described for elderly patients can be incorporated to assess the cost impact of the antimicrobial therapy. The effectiveness of this method might better predict the percentage of patients who favorably respond to the antibiotics under study and might allow for a more accurate estimate of resource consumption associated with the treatment of CAP. In the base-case, a lower total cost for the treatment of CAP in the ertapenem-arm is expected due to the higher proportion of successfully treated patients, making second-line treatments unnecessary and resulting in consequent savings in hospitalization costs.

Under the alternative scenario, in patients with PSI $\leq 3$, the treatment of CAP with ceftriaxone leads to lower total costs compared to the treatment with ertapenem. This result is related to the lower difference in the initial efficacy between ertapenem and ceftriaxone described for those patients. In contrast, for patients with PSI $>3$, the treatment of CAP is less costly when ertapenem is used relative to ceftriaxone. 


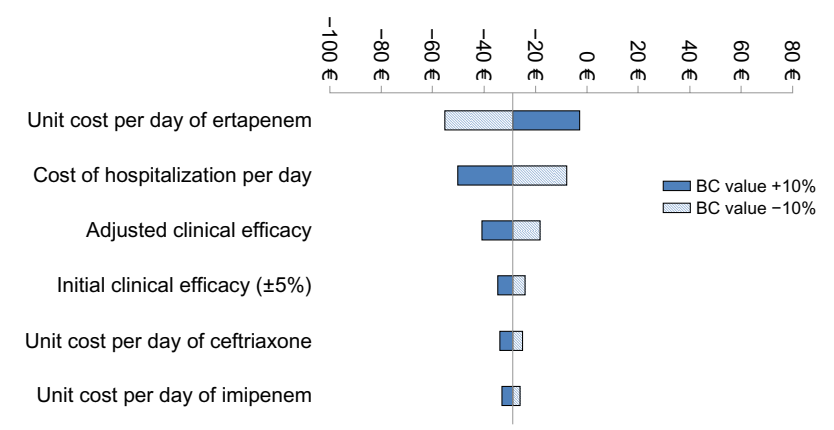

Figure 4 Tornado diagram for the base-case.

Abbreviation: $\mathrm{BC}$, base-case.

This savings confirms that acquisition costs of different antimicrobials may be less significant compared with the costs associated with therapeutic failure or adverse effects. Drug acquisition costs are a primary consideration only if there are no significant differences in treatment outcomes between agents, potential for selection of resistance, and incidence of significant treatment-related adverse events. Thus, a more expensive agent may be a very efficient alternative if it is associated with greater efficacy or better tolerance than a less expensive option.

There are other methods described in the literature for reducing cost when treating patients with CAP. These include administering appropriate empiric antibacterial therapy, based on pharmacodynamic and pharmacokinetic characteristics and providing therapy that facilitates good patient compliance, such as single daily dosing and shorter treatment courses. ${ }^{31}$ According to the one-way sensitivity analysis, LOS was the parameter with the most impact on the cost of CAP management. Under the current cost-containment policies and supported by the evidence from recent studies demonstrating that reductions of hospital stays could reduce costs without compromising patient outcomes, most hospitals are making efforts for optimizing LOS. In a study by Capelastegui et $a 1,{ }^{32}$ the trend in duration of hospitalization for CAP was assessed during 2000-2007, and it was observed that a 2-day decrease in LOS did not increase the likelihood of short-term mortality or hospital readmission. The impact of LOS was extensively studied in our model through different scenarios, confirming the robustness of our evaluation. The results of the probabilistic sensitivity analysis support the finding that ertapenem could be a cost-saving alternative compared to ceftriaxone. Of the 1,000 simulations run in this study, ertapenem showed additional benefits at lower costs in $59 \%$ of the estimates versus ceftriaxone, both for elderly patients ( $>65$ years) and patients with PSI $>3$. In addition, in those cases where ertapenem showed additional benefits and higher costs, the difference in drug cost between ertapenem and ceftriaxone was offset by at least $50 \%$ in $44 \%$ of simulations.

The results obtained in this study suggest that elderly patients with CAP, who often require longer hospitalization periods than younger patients, and patients with severe pneumonia, are two segments of the population that would greatly benefit from those strategies that lead to a shorter duration of hospitalization. Our results are in line with those published in a recent and important study that relates the advanced age and severity of the pneumonia with longer hospitalization periods. ${ }^{33}$

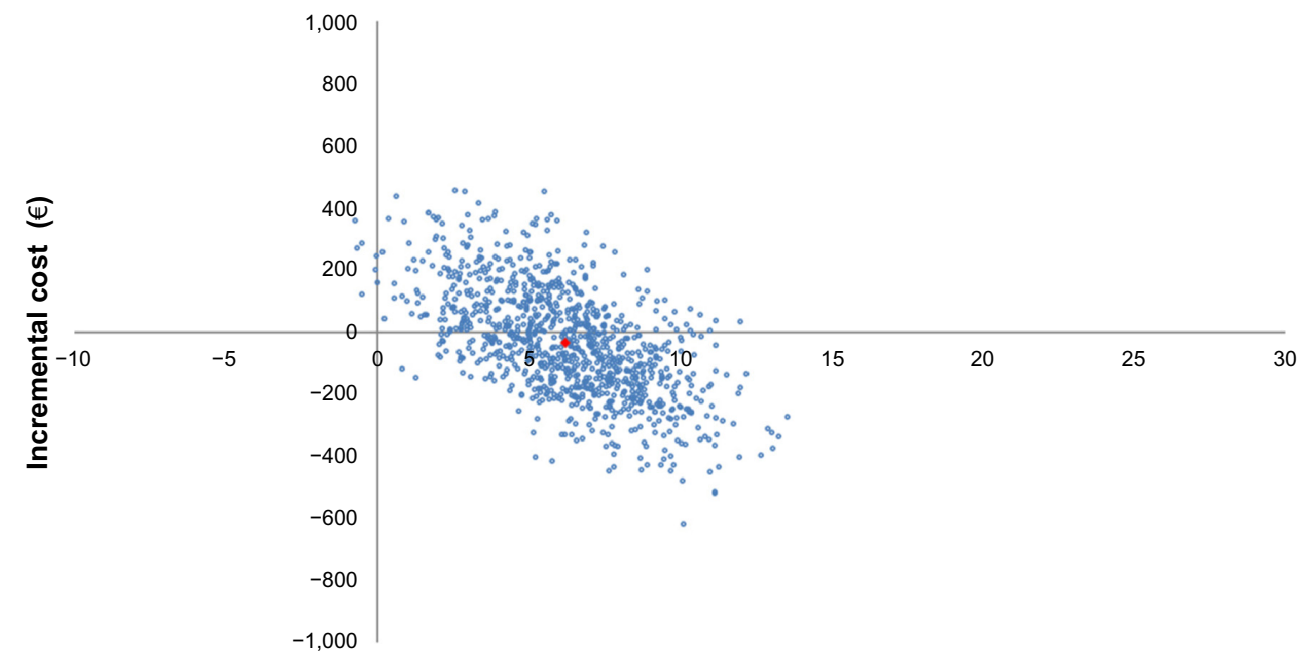

Incremental effectiveness

Figure 5 Cost-effectiveness plot for the base-case scenario (>65 years) comparing ertapenem versus ceftriaxone.

Notes: The figure shows the incremental cost-effectiveness scatter plot derived from the probabilistic sensitivity analysis. Each blue dot represents the result of an iteration of the Monte Carlo simulation. The red dot is the average of the I,000 iterations. 
Table 5 Clinical and economic results of the model for the alternative scenario

\begin{tabular}{|c|c|c|c|c|c|c|}
\hline & \multicolumn{3}{|l|}{ PSI $\leq 3$} & \multicolumn{3}{|l|}{ PSI $>3$} \\
\hline & Ertapenem-arm & Ceftriaxone-arm & Differences & Ertapenem-arm & Ceftriaxone-arm & Differences \\
\hline $\begin{array}{l}\text { First-line clinical failures } \\
\text { avoided }\end{array}$ & $70.3 \%$ & $66.5 \%$ & $3.8 \%$ & $68.3 \%$ & $61.8 \%$ & $6.5 \%$ \\
\hline \multicolumn{7}{|l|}{ Cost per patient } \\
\hline Drug cost per patient & $€ 428$ & $€ 234$ & $€ 194$ & $€ 435$ & $€ 259$ & $€ 176$ \\
\hline $\begin{array}{l}\text { Resource use cost } \\
\text { per patient }\end{array}$ & $€ 4,537$ & $€ 4,665$ & $-€ 128$ & $€ 4,607$ & $€ 4,827$ & $-€ 220$ \\
\hline Total cost & $€ 4,965$ & $€ 4,899$ & $€ 66$ & $€ 5,042$ & $€ 5,086$ & $-€ 44$ \\
\hline
\end{tabular}

Note: The alternative scenario was developed using the clinical data of clinical cure rates for patients with PSI $\leq 3$ and PSI $>3$ from the combined analyses performed by Ortiz-Ruiz et al. ${ }^{15}$

Abbreviation: PSI, pneumonia severity index.

Some limitations of our study must be considered. The etiology data used in this model were obtained from an epidemiology study carried out with 473 patients, aged $\geq 65$, in the region of Tarragona. ${ }^{10}$ More appropriate data might be obtained with a longer study, that includes patients from several regions of Spain, but unfortunately, no other specific study of etiology for elderly patients was found in the literature. In our model, it is assumed that all the patients with CAP are infected uniformly with the pathogens' distribution, but in the clinical setting, patients are monoinfected with a specific pathogen or with several.

The microbial susceptibility profile was obtained from the most recent published studies at the time of this analysis. As new evidence regarding microbial susceptibilities arise, it will be interesting to incorporate this data in the model to assess future outcomes. Additionally, it should be acknowledged that although the most current microbiological evidence has been used, this may not necessarily reflect the precise situation in a given site. Certainly, there can be variability across sites that would influence the results of this study, depending both on the specificities of the microbiological distribution and as a consequence of the differences in the antibiotic drug practices and their impact on the agent and strain selection. Nevertheless, we believe it is very likely that there is a common microbiological background across many sites and geographies, making the broad conclusions of this study valid in a wide range of settings despite their potential differences.

Another limitation of the model in this study is that, due to its short time horizon, it does not account for the antimicrobial resistance rate change over time. Two longer duration studies have shown that when taking the resistance rate change into account, ertapenem yields even more cost savings over time when compared to the alternatives. ${ }^{24,25}$

For patients with clinical suspicion of infection with microorganisms causing atypical pneumonias or in the absence of a demonstrative Gram strain, most hospital guidelines recommend combination therapy with a macrolide. ${ }^{6}$ In this analysis, it was assumed that combination with a macrolide would impact both strategies in a similar way. Thus, only monotherapy with ertapenem or ceftriaxone was considered for cost calculations and efficacy data.

Adverse events were not taken into consideration due to their similar proportion in both ertapenem and ceftriaxone-arms. Moreover, the adverse events that occurred were mild and not associated with extensive costs.

Imipenem was chosen for the second-line antibiotic treatment due to its broad spectrum activity and its recommendation in clinical guidelines. ${ }^{6}$ It is important to note that data for the initial clinical efficacy of imipenem was obtained from a study where imipenem was administered at $1.5 \mathrm{~g}$ per day, ${ }^{18}$ but for cost calculations, the recommended dose of $3 \mathrm{~g}$ per day in Spanish guidelines was considered. ${ }^{6}$ The influence of imipenem cost was studied in the sensitivity analysis, and a very low impact on the base-case results was observed. For the estimation of the health care resources costs consumed during the treatment of CAP, the cost of DRGs was applied due to the absence of detailed cost information on CAP management in Spain.

The recommended regimens for patients with more severe infections include amoxicillin-clavulanic acid administered intravenously, levofloxacin, moxifloxacin, piperacillintazobactam, meropenem, and several cephalosporins. The current study is focused on ertapenem and ceftriaxone given the availability of head-to-head data for clinical efficacy. For future analyses, it would be interesting to include other comparators and to analyze whether the results are transferable to other strategies.

\section{Conclusion}

Despite its limitations, this study provides both clinical and economic insight into the effect of modulating the initial 
clinical efficacy of two antibiotics according to the current microbiological susceptibility profile and the distribution of pathogens for elderly patients. The current study showed that modulating the initial clinical efficacy, the treatment of CAP with ertapenem compared to ceftriaxone could lead to lower health care costs and the benefit of earlier discharge from the hospital for two segments of the Spanish population: elderly patients and patients with severe pneumonia (PSI >3). Further analyses with other comparators are needed to obtain more data on effectiveness and economic impact that can help to validate the model.

\section{Author contributions}

S Grau, V Lozano, A Valladares, and R Cavanillas have participated in acquisition, analysis, and interpretation of data and have been involved in drafting and reviewing the manuscript. G Nocea has participated in the study design and interpretation of data and has critically revised the manuscript. Y Xie has participated in the study design and has critically revised the manuscript.

\section{Disclosure}

This study was funded by Merck Sharp and Dohme. S Grau has received honoraria for speaking at symposia organized on behalf of Pfizer, Astellas, MSD, and Novartis. V Lozano has served as an external consultant for Merck Sharp and Dohme. A Valladares, R Cavanillas, Y Xie, and G Nocea are current employees of Merck Sharp and Dohme. The authors report no other conflicts of interest in this work.

\section{References}

1. Niederman MS, McCombs JS, Unger AN, Kumar A, Popovian R. The cost of treating community-acquired pneumonia. Clin Ther. 1998;20(4):820-837.

2. Garibaldi RA. Epidemiology of community-acquired respiratory tract infections in adults. Incidence, etiology, and impact. Am J Med. 1985;78(6B):32-37.

3. Rajas Naranjo O, Aspa Marco J. 2004: Año de la Neumonía. Consecuencias e impacto científico en Archivos de Bronconeumología [Pneumonia awareness year, 2004: scientific impact through publications in Archivos de Bronconeumología]. Arch Bronconeumol. 2006;42(10):541-552. Spanish.

4. Bayas JM, Vilella A, San-Martín M, González A, Conesa A, Asenjo MA. Impacto Sanitario de los ingresos por neumonía en un hospital de tercer nivel [Impact of hospital admissions for pneumonia in a tertiary Spanish hospital]. Med Clin (Barc). 2001;116(18):694-695. Spanish.

5. Blanquer J, Sanz F. Neumonía adquirida en la comunidad [Communityacquired pneumonia]. Arch Bronconeumol. 2010;46(Suppl 7):26-30. Spanish.

6. Menéndez R, Torres A, Aspa J, Capelastequi A, Prat C, Rodríquez de Castro F. Neumonía adquirida en la comunidad. Nueva normativa de la Sociedad Española de Neumología y Cirugía Torácica (SEPAR) [Community-acquired pneumonia. New guidelines of the Spanish Society of Chest Disease and Thoracic Surgery (SEPAR)]. Arch Bronconeumol. 2010;46(10):543-558. Spanish.
7. Burkhardt O, Derendorf H, Welte T. Ertapenem: the new carbapenem 5 years after first FDA licensing for clinical practice. Expert Opin Pharmacother. 2007:8(2):237-256.

8. Epstein JS, Hasselquist SM, Simon GL. Efficacy of ceftriaxone in serious bacterial infections. Antimicrob Agents Chemother. 1982;21(3): 402-406.

9. Murcia JM, González-Comeche, Marín A, et al; SCAPE Study Group. Clinical response to ertapenem in severe community-acquires pneumonia: a retrospective series in an elderly population. Clin Microbiol Infect. 2009;15(11):1046-1050.

10. Vila-Corcoles A, Ochoa-Gondar O, Rodriguez-Blanco T, Raga-Luria X, Gomez-Bertomeu F; EPIVAC Study Group. Epidemiology of community-acquired pneumonia in older adults: a population-based study. Respir Med. 2009;103(2):309-316.

11. Fernández-Sabé N, Carratalà J, Rosón B, et al. Community-acquired pneumonia in very elderly patients: causative organisms, clinical characteristics, and outcomes. Medicine (Baltimore). 2003;82(3):159-169.

12. Mandell LA, Wunderink RG, Anzueto A, et al; Infectious Diseases Society of America; American Thoracic Society. Infectious Diseases Society of America/American Thoracic Society consensus guidelines on the management of community-acquired pneumonia in adults. Clin Infect Dis. 2007;44(Suppl 2):S27-S72.

13. Ortiz-Ruiz G, Caballero-Lopez J, Friedland IR, Woods GL, Carides A; Protocol 018 Ertapenem Community-Acquired Pneumonia Study Group. A study evaluating the efficacy, safety, and tolerability of ertapenem versus ceftriaxone for the treatment of community-acquired pneumonia in adults. Clin Infect Dis. 2002;34(8):1076-1083.

14. Vetter N, Cambronero-Hernandez E, Rohlf J, et al. Protocol 020 Study Group. A prospective, randomized, double-blind multicenter comparison of parenteral ertapenem and ceftriaxone for the treatment of hospitalized adults with community-acquired pneumonia. Clin Ther. 2002;24(11):1770-1785.

15. Ortiz-Ruiz G, Vetter N, Isaacs R, Carides A, Woods GL, Friedland I. Ertapenem versus ceftriaxone for the treatment of communityacquired pneumonia in adults: combined analysis of two multicentre randomized, double-blind studies. J Antimicrob Chemother. 2004;53(Suppl 2):ii59-ii66.

16. Woods GL, Isaacs RD, McCarroll KA, Friedland IR. Ertapenem therapy for community-acquired pneumonia in the elderly. $J \mathrm{Am}$ Geriatr Soc. 2003;51(11):1526-1532.

17. Arancibia F, Ewig S, Martinez JA, et al. Antimicrobial treatment failures in patients with community-acquired pneumonia: causes and prognostic implications. Am J Respir Crit Care Med. 2000;162(1):154-160.

18. Romanelli G, Cravarezza P, Pozzi A, et al. Carbapenems in the treatment of severe community-acquired pneumonia in hospitalized elderly patients: a comparative study against standard therapy. $J$ Chemother. 2002;14(6):609-617.

19. Fine MJ, Auble TE, Yealy DM, et al. A prediction rule to identify low-risk patients with community-acquired pneumonia. $N$ Engl $J$ Med. 1997;336(4):243-250.

20. Livermore DM, Carter MW, Bagel S, et al. In vitro activities of ertapenem (MK-0826) against recent clinical bacteria collected in Europe and Australia. Antimicrob Agents Chemother. 2001;45(6): 1860-1867.

21. Pérez-Trallero E, Marimón JM, Larruskain J, Alonso M, Ercibengoa M. Antimicrobial susceptibilities and serotypes of Streptococcus pneumoniae isolates from elderly patients with pneumonia and acute exacerbation of chronic obstructive pulmonary disease. Antimicrob Agents Chemother. 2011;55(6):2729-2734.

22. Gobernado M, Sanz-Rodríguez C, Villanueva R, Torroba L, Redondo E, González-Esteban J. Actividad in vitro de ertapenem frente a cepas bacterianas clínicas aisladas en 69 centros médicos españoles (Estudio E-test) [In vitro activity of ertapenem against clinical bacterial isolates in 69 Spanish medical centers (E-test study)]. Rev Esp Quimioter. 2007;20(4):395-408. Spanish.

23. Marchese A, Gualco L, Schito AM, Debbia EA, Schito GC. In vitro activity of ertapenem against selected respiratory pathogens. J Antimicrob Chemother. 2004;54(5):944-951. 
24. Jansen JP, Kumar R, Carmeli Y. Accounting for the development of antibacterial resistance in the cost effectiveness of ertapenem versus piperacillin/tazobactam in the treatment of diabetic foot infections in the UK. Pharmacoeconomics. 2009;27(12):1045-1056.

25. Jansen JP, Kumar R, Carmeli Y. Cost-effectiveness evaluation of ertapenem versus piperacillin/tazobactam in the treatment of complicated intraabdominal infections accounting for antibiotic resistance. Value Health. 2009;12(2):234-244.

26. Menéndez R, Torres A, Zalacaín R, et al; Neumofail Group. Risk factors of treatment failure in community acquired pneumonia: implications for disease outcome. Thorax. 2004;59(11):960-965.

27. Hospital discharge register-(Conjunto mínimo de datos CMBD). Pestadistico.msc.es [homepage on the Internet]. Madrid: Spanish Ministry of Health. Available from: http://pestadistico.msc.es./ PEMSC25/. Accessed October 30, 2013.

28. Royal Decree-law 4/2010, May 26 [homepage on the Internet]. Información orientativa sobre los factores de conversión del PVL a PVP y PVP IVA, aplicables a partir del 1 de julio de 2010. Madrid: Spanish Ministry of Health. Available from: http://www.msps.es/profesionales/farmacia/pdf/ margenesFactoresConversion.pdf. Accessed October 30, 2013.
29. Spanish General Council of Official Colleges of Pharmacists - Botplus. [homepage on the Internet] Available from: https://botplusweb. portalfarma.com/. Accessed October 30, 2013.

30. Royal Decree-law 8/2010, May 20 [homepage on the Internet]. Madrid: Spanish Ministry of Health. Available from: http://www.msps.es/profesionales/farmacia/notasInfor.htm. Accessed October 30, 2013.

31. Nightingale CH, Ambrose P, File TM Jr, editors. Community-Acquired Respiratory Infections: Antimicrobial Management. 2nd ed. New York: Marcel Dekker Inc; 2005.

32. Capelastegui A, España PP, Quintana JM, et al. Declining length of hospital stay for pneumonia and postdischarge outcomes. Am J Med. 2008;121(10):845-852.

33. Garcia-Vidal C, Carratalà J, Díaz V, et al. Factores relacionados con una estancia media hospitalaria prolongada en la neumonía adquirida en la comunidad [Factors associated with prolonged hospital stay in community-acquired pneumonia]. Enferm Infecc Microbiol Clin. 2009;27(3):160-164. Spanish.
ClinicoEconomics and Outcomes Research

\section{Publish your work in this journal}

ClinicoEconomics \& Outcomes Research is an international, peerreviewed open-access journal focusing on Health Technology Assessment, Pharmacoeconomics and Outcomes Research in the areas of diagnosis, medical devices, and clinical, surgical and pharmacological intervention. The economic impact of health policy and health systems

\section{Dovepress}

organization also constitute important areas of coverage. The manuscript management system is completely online and includes a very quick and fair peer-review system, which is all easy to use. Visit http://www.dovepress.com/testimonials.php to read real quotes from published authors.

Submit your manuscript here: http://www.dovepress.com/clinicoeconomics-and-outcomes-research-journal 